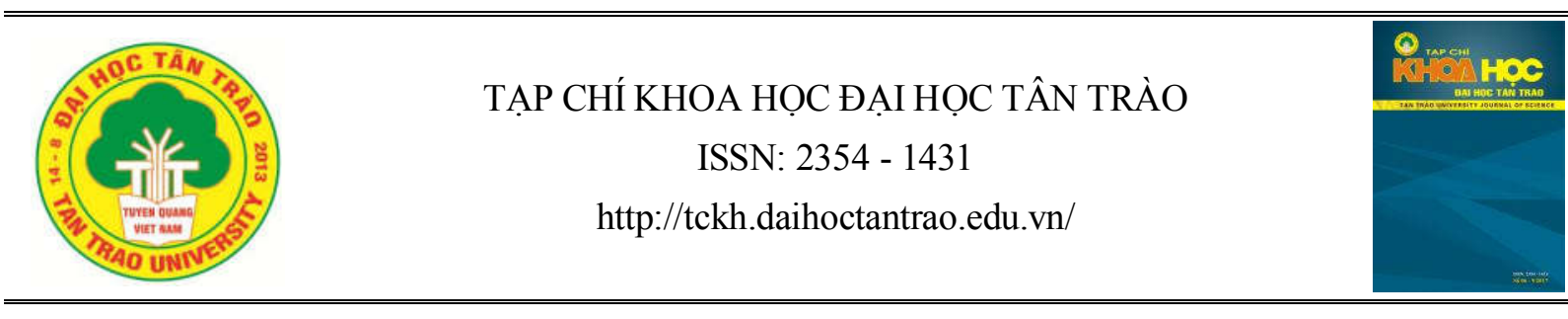

\title{
Sự khác biệt trong diễn xướng hát đối đáp dân ca trũ̃ tình sinh hoạt của người Tày và người Thái
}

\author{
Hà Xuân Hương $a^{a^{*}}$ \\ ${ }^{a}$ Trường Đại học Khoa học, Đại học Thái Nguyên \\ *Email: haxuanhuong85@gmail.com
}

\section{Thông tin bài viết}

Ngày nhận bài:

$02 / 5 / 2019$

Ngày duyệt đăng:

$10 / 6 / 2019$

Tù khóa:

Sư khác biệt; diến xướng hát đối đáp; dân ca trũ tình sinh hoạt; ngươi Tày; ngưòi Thái.

\section{Tóm tắt}

Là những dân tộc chủ thể văn hóa vùng Đông Bắc và Tây Bắc, người Tày và người Thái có đời sống văn hóa vô cùng đặc sắc, trong đó phải kể đến các diễn xướng hát đối đáp dân ca trữ tình sinh hoạt. Qua so sánh, chúng tôi thấy diễn xướng hát đối đáp dân ca trữ tình sinh hoạt Tày, Thái có sự khác biệt về tính tổ chức, không gian, thời gian, dạng diễn xướng theo sách, sự tham gia của vũ đạo vào diễn xướng. Từ đó, có thể thấy diễn xướng hát đối đáp dân ca trữ tình sinh hoạt của người Tày nổi bật ở tính tổ chức, sự ổn định; diễn xướng hát đối đáp dân ca trữ tình sinh hoạt của người Thái nổi bật ở tính tự do, sự sinh động. Những điểm khác biệt này là cơ sở để nhận thức về bản sắc văn hóa của hai dân tộc Tày, Thái.

\section{1. Đặt vấn đề}

Các tài liệu nghiên cứu đều khẳng định văn học dân gian là những sáng tác ngôn từ, càng ở giai đoạn sau, tính nghệ thuật của nó càng thể hiện rõ. Khi viết về văn học dân gian, văn hóa dân gian, nhiều tác giả đã đề cập đến tính diễn xướng với những khái niệm như phương thức diễn xướng, khâu diễn xướng, các diễn xướng folklore, các kiểu trình diễn nghệ thuật dân gian. Trong đó, cốt lõi của thuật ngữ diễn xướng là chỉ việc thể hiện, trình bày các sáng tác văn nghệ trong các hoàn cảnh cụ thể của đời sống, do con người đảm nhiệm, bao gồm các yếu tố: thời gian, địa điểm, âm thanh, vũ đạo... Ở bài viết này, chúng tôi quan tâm đến các đặc điểm diễn xướng của dân ca trữ tình sinh hoạt (DCTTSH) Tày, Thái, với hình thức diễn xướng là hát đối đáp. Hướng tới DCTTSH, chúng tôi muốn tập trung vào bộ phận dân ca sinh hoạt liên quan đến người lớn, không bao gồm hát ru và đồng dao, bởi lẽ, các đặc điểm diễn xướng của DCTTSH phong phú, hàm chứa mối liên hệ sâu xa, nhiều tầng bậc với lịch sử, văn hóa, xã hội tộc người mà nếu so sánh sẽ thấy được rõ ràng hơn sự khác biệt trong văn hóa các tộc người.
Ở nước ta, giới nghiên cứu văn học dân gian thống nhất cho rằng, văn học dân gian cổ truyền là những sáng tác lưu hành từ Cách mạng tháng Tám năm 1945 trở về trước. Nếu như ở văn học dân gian của người Kinh, cho đến gần đây, các đặc điểm của diễn xướng dân ca chỉ còn có thể quan sát được qua việc phục dựng hát quan họ, dân ca ví, giặm Nghệ Tĩnh..., thì ở văn học dân gian Tày, Thái, chúng ta vẫn quan sát được các diễn xướng hát đối đáp trong thực tế, dù rằng mức độ không nhiều. Ngoài ra, qua sự ghi chép của các nhà nghiên cứu và sự hồi cố của các nghệ nhân, chúng ta vẫn phục dựng lại được diễn xướng của DCTTSH Tày, Thái. Điều đó là cơ sở để chúng ta chỉ ra những điểm khác biệt của diễn xướng hát đối đáp DCTTSH của người Tày và người Thái - hai dân tộc chủ thể văn hóa vùng Đông Bắc và Tây Bắc, góp phần nhận thức về bản sắc văn hóa của hai dân tộc này.

2. Sự khác biệt về diễn xướng hát đối đáp dân ca trữ tình sinh hoạt của hai dân tộc Tày, Thái

\subsection{Tính tổ chức của diễn xướng}

Hát đối đáp DCTTSH bao gồm hai cấp độ xét về mặt tổ chức: 
Hát lẻ: Đây là dạng diễn xướng không có sự chuẩn bị từ trước, không có nghi thức tổ chức chặt chẽ, mang tính tự phát. Diễn xướng có thể xảy ra tự nhiên, bất chợt vào bất cứ lúc nào, trong khoảng thời gian không dài. Đó là lúc lao động trên nương rẫy, trong rừng hay nơi đồng ruộng, cũng có thể là trong đời sống thường ngày. Người ta hát vào buổi sáng, ban chiều, hay những đêm trăng thơ mộng nơi bản làng mù sương. Bởi không tuân theo một nghi thức tổ chức nào nên các diễn xướng này đều sử dụng dạng hát tự do. Phần ngôn từ nghệ thuật tham gia vào diễn xướng chỉ là những câu hát đơn hoặc hát đối đáp lẻ tẻ. Các cá nhân tham gia diễn xướng chính là những người tham gia vào sáng tạo dân ca. Hoạt động nghệ thuật gắn bó chặt chẽ với tính vui chơi giải trí, trao đổi tình cảm, với môi trường lao động và đời sống thường ngày. Như thế, đây là dạng thức nguyên hợp, tồn tại ở trạng thái tự nhiên nhất. Nó vốn tồn tại ở các thể loại dân ca, nhưng hiện nay dạng thức này về cơ bản đã mai một nhiều.

Hát cuộc: Đây là hình thức diễn xướng có tổ chức, có thể thức, lề lối được quy định rõ ràng, chặt chẽ. Hình thức này dần tách rời khỏi thực tiễn hàng ngày, song không vì vậy mà tách khỏi cuộc sống, môi trường lao động. Trong loại diễn xướng này, công tác chuẩn bị, cách thức diễn xướng đều có bài bản thứ tự trước sau. Chức năng giao duyên của dân ca giao duyên dần được biến thành chức năng giao lưu tình cảm giữa những con người tham gia vào cuộc hát. Hơn thế, có khi nó còn được nâng tầm thành cuộc thi tài mang yếu tố nghệ thuật. Tính tự giác của dạng hát cuộc đã thay thế cho tính tự phát của dạng hát lẻ nguyên sơ. Ở những cuộc hát có quy mô lớn, đặc biệt là cuộc hát có tính thi tài, diễn xướng cuộc thường do những người đứng đầu làng bản hoặc một gia đình khá giả trong bản đứng ra tổ chức, hoặc tài trợ để tổ chức.

Ở người Thái Tây Bắc tồn tại cả hai cách thức tổ chức diễn xướng DCTTSH này. Cách thức tổ chức thứ nhất có thể gặp ở diễn xướng khắp xáng buôn, khắp kho nay choi. Chẳng hạn, khắp khơ nay chơi là điệu hát rong chơi, mang tính chất vui bâng quơ, thường dành cho lứa tuổi thanh niên còn thích bông đùa và hát vào khoảng thời gian nông nhàn. Họ hát khi đi chơi ngoài đường, trên cánh đồng hoặc lúc vào rừng. Khắp xáng buôn là điệu hát giải sầu, được hát lúc vắng vẻ với tiếng hát to, ngân dài như than vãn để trải lòng về những chuyện tình cảm riêng tư, khó chia sẻ. Trong thời gian điền dã cùng sinh viên trường Đại học Khoa học Thái Nguyên tại Sơn A (Văn Chấn - Yên Bái), chúng tôi thường được nghe điệu khắp kho nay chơi của các nam thanh niên nơi đây. Mở đầu là tiếng sáo pí tam (sáo nối), tiếp sau đó là tiếng hát to, vang lên oang oang ngoài đường. Bên cạnh đó, các điệu khắp báo xao lại thuộc dạng hát cuộc, tức hát có thể thức, lề lối đàng hoàng. Khắp báo xao có thể diễn ra trong nhiều dịp: đám cưới, làm nhà, lễ hội...; được tổ chức ngoài trời hoặc trong nhà. Theo ghi nhận của chúng tôi trong chuyến thực địa tại Sơn A (Văn Chấn - Yên Bái) với sự chứng kiến trực tiếp lễ hội Lồng tồng đầu xuân và một đám cưới, một lễ làm nhà tại đây, thì hình thức tổ chức khắp báo xao trong nhà với tính chất như một cuộc thi tài là phổ biến. Người ta bày mâm hát cho bên nam và bên nữ, có quy ước rõ ràng về cuộc thi. Khi được tổ chức ở nơi giao lưu cộng đồng như vậy, khắp báo xao ít được tổ chức theo hình thức hát cặp mà hát cùng lúc nhiều cặp, mang tính tập thể. Mục đích tỏ tình thầm kín của cá nhân được thay bằng mục đích thi tài. Tuy thế, đồng bào vẫn giữ nguyên lời bài hát như trong truyền thống, ít có sự sửa đổi.

Trong khi đó, ở người Tày Đông Bắc, dấu ấn về dạng hát lẻ, không có tổ chức rất mờ nhạt. Trong quá khứ, dạng hát tự do này từng khá phổ biến với phuối pác, phuối rọi, luợn rọi khi người ta gặp nhau ngoài đường, ngoài chợ, khi làm nương rẫy hoặc vui chơi nơi chân núi. Tuy thế, ngày nay, chúng ta khó được chứng kiến dạng hát này của người Tày. Trong toàn bộ quá trình điền dã tại một số nơi thuộc Lạng Sơn, Bắc Kạn, Cao Bằng, chúng tôi không hề gặp dạng hát này. Dạng thức tổ chức hát cuộc với thể thức, lề lối ổn định, rõ ràng nổi bật hơn cả. Diễn xướng lươnn sluoong, lượn then, lượn cọi, iếu... thuộc dạng này. Chẳng hạn, diễn xướng iếu quy định người tham gia cuộc hát phải là trai gái chưa kết hôn. Nếu đã có vợ có chồng rồi thì họ không được phép iếu nữa. Hơn thế, những người quen biết nhau từ trước như người cùng bản, cùng làng, cùng họ thì không iếu với nhau. Đối tượng của iếu phải là người lạ, từ nơi khác đến. Nhìn chung, bối cảnh cho cuộc hát có lề lối của người Tày thường là trong ngày lễ hội, khách nghỉ tại bản làng. Lúc này chủ làng trao đổi thống nhất với chủ nhà có khách trọ, một tốp thanh niên của bản kéo đến nhà có khách trọ, lươn mời khách tham gia cuộc lươnn. Khách có lời đáp lại là bắt đầu cuộc lượn ứng tác giữa khách và tốp thanh niên. Sự ứng tác của đôi bên đều nằm trong phạm vi các chủ đề của lươn slương, lươn cọi, iếu... với những khuôn mẫu, công thức có sẵn cho người hát học thuộc và vận dụng để sáng tạo, tái tạo. Trong các loại hát cuộc của người Tày, lươn cọi là hình thức diễn xướng có tính tổ chức cao nhất với sự tham gia của slấy cá (thầy dẫn) với vai trò dẫn lượn, sự tồn tại của sách hát dành cho bên nam và sách hát dành cho bên nữ. Ở các cuộc hát trong và sau lễ hội Lồng tồng của người Tày mà chúng tôi được tham dự ở Na Rì (Bắc Kạn), chúng tôi nhận thấy sự có mặt của các diễn xướng lươn sluơng và diễn xướng luợn cọi. Trong đó, diễn xướng lươn sluoong thường được tổ chức 
với mục đích thi tài, diễn xướng luợn cọi thường được tổ chức với mục đích giao lưu tình cảm. Phần lời của các bài hát này đã được viết mới hoặc bổ sung, sửa đổi cho phù hợp với hoàn cảnh xã hội hiện đại.

\subsection{Không gian, thời gian của diễn xướng}

Cùng là hát đối đáp nhưng không gian, thời gian diễn xướng ở mỗi dân tộc lại có những nét khác nhau. Ở người Tày có các hình thức luợn trong nhà, luợn ngoài đường, luợn lễ họi. Trong đó, các loại lươn lễ hội, luợn trong nhà phổ biến hơn so với lươn ngoài đường. Tương ứng với các hình thức luợn ấy là các loại không gian, thời gian khác nhau. Luợn ngoài đường là những cuộc hát mang tính chất tự do, ngẫu hứng, diễn ra trong những dịp gặp nhau không hẹn trước, có không gian là những địa điểm mang tính chất tự nhiên như các quang cảnh hội xuân, bên lề phiên chợ, trên các gò đồi, ven suối, đường lên nương, về bản... giống trong diễn xướng sli của người Nùng. Khi đó, họ sẽ dùng phuối pác, phuối rọi là lối nói có vần điệu, mang tính hồn nhiên, dân dã cao để trao đổi tình cảm. Luợn lễ hội là hình thức cuộc hát được tổ chức tại không gian lễ hội như lễ hội lồng tồng, lễ hội Nàng Hai, với thời gian là sau phần lễ. Cuộc luợn có thể kéo dài từ ngày đến đêm tối, song khi đêm tối, không gian của cuộc luợn thường được chuyển vào trong nhà. Lươn trong nhà là cuộc lươn có tính tổ chức cao với lề lối, quy củ khá rõ ràng. Về thời gian nói chung, các cuộc lươn thường được tổ chức vào những dịp lễ hội của bản làng hoặc khi có sự gặp gỡ giữa chủ và khách như lễ cưới, lẩu then, mừng nhà mới, khách lạ đến chơi. Về không gian, thời gian cụ thể, cuộc luợn được tổ chức ở trong nhà và vào ban đêm. Quanh bếp lửa, phía mặt trên (nả nura) là chỗ dành cho nam giới ngồi. Phía sau (nả đâu) là chỗ ngồi của nữ giới. Phía dưới (nả tâủ), gần chạn bát, bếp nấu là chỗ của người nấu nướng phục vụ cuộc hát. Phía ngoài (nả noỏc) gần cầu thang lên xuống là chỗ ngồi của người dự nghe. Nhà lúc này không thuần túy là không gian sinh hoạt của cuộc sống con người mà còn mang chức năng của thính phòng, được đặt trong khoảng không gian giữa nhà. Cuộc luợn được thực hiện từ hai chủ thể: chủ bản và khách xa, có thính giả thưởng thức và hỗ trợ. Thường, trai làng nọ hát với gái làng kia hoặc ngược lại. Hiếm khi trai gái cùng một bản luợn với nhau. Trong không gian hẹp ấy, tại các bản làng, tiếng lươn cất lên phần nào phá tan không khí tĩnh lặng, buồn tẻ, u tịch của núi rừng. Chính trong không gian yên ắng này, lời lươn càng lôi cuốn và tăng thêm sức truyền cảm cho người nghe, góp phần sáng tạo, tái tạo văn hóa truyền thống qua nhiều thế hệ.

Ở người Thái, diễn xướng khắp tự do hơn về không gian, thời gian. Họ có thể hát trong không gian lễ hội: lễ hội Hoa ban, lễ hội Hạn khuống, lễ hội Xòe chiêng, lễ hội Kin pang then ... Ngoài ra, người Thái còn hát bất kể khi nào: lúc lao động (làm nương, vào rừng kiếm củi, nhặt rêu dưới suối...), lúc trăng sáng đẹp trời, lúc đi chơi ngoài đường, lúc hò hẹn tâm tình... Họ hẹn nhau cùng hát ở nhà mình, nhà bạn; sân trước nhà hay bãi ven suối, ven bản; bên mâm cơm, mâm rượu...

Như thế, với sự phổ biến của luợn lễ hội và luợn trong nhà, các đặc điểm không gian, thời gian các cuộc hát luợn của người Tày dần định hình ở một thể thức tương đối ổn định và công khai, ít nhiều mang tính chỉn chu, nghiêm túc, đòi hỏi sự chuẩn bị từ trước. Trong khi đó, các cuộc hát của người Thái diễn ra thường xuyên hơn, không câu nệ về thời gian, địa điểm.

\subsection{Dạng thức diễn xướng theo sách}

Trong diễn xướng dân ca, yếu tố ứng tác cho phép người ta sáng tạo ra những phiến đoạn, những bài hát mới. Điều đó làm nên dạng thức diễn xướng tự do. Diễn xướng DCTTSH của dân tộc nào cũng có dạng thức này. Song, riêng ở người Tày, chúng tôi nhận thấy có thêm dạng thức diễn xướng theo sách.

Luợn sluơng của người Tày về cơ bản thuộc dạng diễn xướng tự do. Các bài hát đều hoặc nhập tâm, hoặc ứng khẩu chứ không cần có thầy dẫn như trong diễn xướng lươn cọi. Sau phần hát chào mời là phần hát tâm tình của nam nữ thanh niên Tày. Những lời hát được hát lên theo lối ứng tác, đối đáp tự do, tùy nghi hoàn cảnh, tâm trạng của đôi bên mà đưa ra những lời đáp cho hợp ý, đẹp tình. Tuy thế, trong luợn sluoong, bên cạnh một số đường lươn mang tính tự do, ứng tác như luợn nải, luợn khan, luợn kiết, còn có sự xuất hiện của lươn tuổng là một đường lươn đòi hỏi hát theo sách. Do các bài luợn tuổng dài, khó thuộc, khó nhớ nên khi luợn, đối tượng nam có thể xem sách luợn trước một khổ rồi đọc cho nữ ngân khổ tiếp theo. Quá trình luợn cũng có thể có sự hỗ trợ từ người thứ ba - một người lớn tuổi thuộc nhiều bài với vai trò mách luợn giúp cặp đôi hát tiếp. Lúc đã thành cặp, họ ngồi tựa lưng vào nhau mà luợn. Các cặp đôi khi luợn thường vừa luợn vừa dừng lại trò chuyện, ăn trầu, uống nước. Như thế, luợn sluoong cũng có sách nôm nhưng thường làm căn cứ cho các bên nam học thuộc nhập tâm hoặc chỉ xem qua khi luợn tuổng. Đặc biệt, chỉ có quyển cho bên hỏi chứ không có quyển cho bên đáp. Khi luợn thì bên nam luợn trước, bên nữ lựa lời đối đáp. Cho nên, trong lươn slưong mới có chuyện thi tài, có bên thắng bên thua.

Độ dài của các bài luợn cọi là một thách thức đối với trí nhớ của người lao động. Trong luợn cọi có những cung dài tới vài trăm câu rất khó nhớ. Khi diễn xướng, phải hát nhiều cung như thế chứ không phải chỉ một cung. Cho 
nên, riêng ở luợn cọi, khi diễn xướng bắt buộc phải có slấy cá để pjấy lươn (có nơi gọi là Tạy lươn, là hành động đọc cho mỗi bên ngâm đối đáp). Bên chủa bản phải tìm cho được slấy cá để pjấy luợn. Slấy cá sẽ căn cứ vào sách hướng dẫn hát giao duyên lươn cọi để dẫn lượn. Sách luợn cọi bao giờ cũng gồm hai quyển, quyển cho bên nam và quyển cho bên nữ, hay chính là quyển cho bên hỏi và quyển cho bên đáp. Diễn xướng luợn cọi, dù chỉ diễn ra trong một buổi hay kéo dài tận nhiều ngày đêm thì cũng đều tuân theo trật tự do slấy cá hướng dẫn. Hình thức đối đáp giữa hai bên trong cuộc luợn chính thức đều do slấy cá căn cứ vào sách mà hướng dẫn bằng tàm pẹc (nói trơn đi trước). Vì đề cao vai trò cá nhân của slấy cá và sách như thế nên trong diễn xướng luợn cọi, người ta không đặt vấn đề thi tài, không có bên thắng bên thua như trong diễn xướng luợn sluơng.

Cụ thể một cuộc lươn cọi như sau: Mở đầu cuộc lrợn là những lời khuyên mời nhưng nó không ngắn như trong luợn sluơng mà biên độ mở rộng ra đến mấy trăm câu. Lời mời luợn có lúc khiêm nhường, thể hiện tập quán mến khách của tộc người, có lúc lại bóng gió, ám chỉ bằng những lí lẽ để đối phương buộc phải lên tiếng đáp trả. Sau khi khách trả lời thì cuộc hát đi vào trật tự đúng như sách mà slấy cá sẽ là người hướng dẫ. Trật tự ây là: Có bạn phương xa đến bản. Cuộc hành trình vào bản Tày được miêu tả hết sức tỉ mỉ từ xa lại gần. Bước chân đến đó, khách thấy đường rộng thênh thang, thấy cây đa, thây đồng ruộng trù phú với cây cối quen thuộc, vườn tược tầng tầng lớp lớp, thấy mỏ nước, rồi khách tới cổng ngõ thấy nhà sàn với những cánh cửa khéo vẽ, trâu chó đầy dưới sàn, thấy cuộc sống nông nghiệp với những gia cầm gia súc thân quen. Sau cùng là các tổ chức làng bản ở địa phương cùng những gái trai tài giỏi, đẹp xinh - tinh hoa của làng, bản ấy. Có thể nói, luợn cọi không chỉ là bức tranh toàn cảnh về đời sống người Tày mà còn là chiếc cầu trao đổi tâm tình yêu mến của nam nữ thanh niên, từ nhu cầu làm quen, tìm hiểu cho đến thở than, trách móc, than ước. Bên cạnh đó, luợn cọi còn phản ánh thế giới quan phong phú của đồng bào Tày với quan niệm về một thế giới vũ trụ ba tầng: mường trời, trần gian và Long Vương. Trí tưởng tượng đã đưa con người ngao du khắp cả mường trời và Long Vương, thực hiện những điều mong ước sâu xa liên quan đến tình yêu. Trở về mặt đất, họ dặn dò nhau nhớ kĩ chuyến đi và tâm tình đã gửi trao ấy. Lượn cọi dành một dung lượng khá lớn cho các cung mừng vùng, mừng gia cảnh... và các cung thể hiện thế giới quan của người Tày như lên mường trời, vào thuyền cùng thầy... Tất cả các cung luợn này cũng đều phải tuyệt đối tuân thủ theo sách và do slấy cá làm thầy dẫn.
Trong khi đó, ở diễn xướng DCTTSH của người Thái, không có sự xuất hiện của dạng thức hát theo sách. Với sự xuất hiện của dạng thức này, diễn xướng DCTTSH Tày ngày càng tiến tới chuyên nghiệp hóa. Ngày nay, cùng với quá trình ảnh hưởng sâu rộng của văn hóa hiện đại vào đời sống cư dân Tày, số người nhập tâm thuộc lời và biết hát các điệu DCTTSH ngày càng ít, chỉ còn số ít người già và các nghệ nhân làm được điều này. Cho nên, những người không thuộc lời muốn tham gia cuộc hát hầu như đều cần đến vai trò của sách. Dạng thức hát theo sách lúc này không chỉ xuất hiện trong các bài hát lươn cọi và các chương luợn tuổng, luợn sủ của luợn sluoong mà còn xuất hiện cả trong các bài hát thuộc nhóm khác như luợn nàng ói

\subsection{Sụ tham gia của vũ đạo vào diễn xướng}

Trong diễn xướng DCTTSH Thái, có sự tham gia của vũ đạo dân gian là các điệu múa xòe đặc trưng của tộc người này, chẳng hạn như khi diễn xướng khắp xe. Trên thực tế, DCTTSH không chỉ có chức năng trao đổi tình cảm cá nhân, riêng tư mà còn tham gia vào các cuộc vui như lễ hội, đám cưới, đám mừng nhà mới... với tư cách một phương tiện giải trí và đoàn kết cộng đồng tộc người. Ở đây, sinh hoạt nghi lễ đã kết hợp sống động với sinh hoạt có tính thế tục, tạo nên những sinh hoạt văn hóa đặc sắc. Trong không gian các lễ hội Xòe chiêng, Hoa ban..., người Thái say mê theo lời ca dịu ngọt, trống chiêng nhịp nhàng và những điệu xòe quyến rũ. Người Thái có nhiều điệu xòe nổi tiếng nhu: khắm khen (nắm tay nhau xòe vòng tròn), khắm khăn moi lảu (nâng khăn mời rượu), phá xi (xòe bổ bốn), nhôm khăn (tung khăn), đổn hôn (tiến, lùi trong cung vòng tròn), óm lọm tốp $m u$ (vòng tròn vỗ tay). Múa xòe là một sinh hoạt văn hóa dân gian không thể thiếu trong các lễ hội mùa xuân, hội mùa và đám cưới của đồng bào Thái. Già trẻ, gái trai đều yêu múa xòe. Bên ánh lửa bập bùng, trong tiếng trống, chiêng nhịp nhàng, điệu múa xòe không thể thiếu sự góp mặt của những điệu DCTTSH tình tứ, nồng say. Người Thái quan niệm múa xòe là phải vui. Vì thế, thanh niên nam nữ hát múa xòe thường hát những bài hát vui, ca ngợi bản mường và công đức người đứng đầu, hoặc hát làn điệu khắp báo xao, một bên hỏi, kể chuyện, bên kia hát đáp lại. Cứ thế, họ vừa hát vừa múa, chơi vui đến khuya không chán. Sở dĩ có sự hiện diện của vũ đạo dân gian vào diễn xướng DCTTSH Thái như thế là bắt nguồn từ việc nghệ thuật múa của tộc người này khá phát triển và đạt đến sự đặc sắc.

Cho đến nay, sự kết hợp giữa múa xòe với diễn xướng DCTTSH ở dân tộc Thái vẫn được duy trì và ngày càng được chú trọng bảo lưu, phát triển. Tham gia các lễ hội đầu xuân ở cấp thôn, bản như thôn Co Cọi 2 (xã Sơn $\mathrm{A}$ ) và bản 
Tào (xã Hạnh Sơn) thuộc huyện Văn Chấn (Yên Bái), chúng tôi nhận thấy hầu hết phụ nữ trong thôn đều biết múa xòe. Mọi người đều rất hào hứng với việc tham gia múa xòe và hát trong các lễ hội đó. Phần hấp dẫn nhất của lễ hội, thu hút sự cộng cảm của cả tập thể bao giờ cũng là phần múa xòe kết hợp với làn điệu khắp báo xao.

Trong khi đó, diễn xướng DCTTSH Tày cũng góp vui trong các lễ hội của người Tày như lễ hội Lồng tồng, lễ hội Nàng Hai, song chúng tôi không thấy có sự tham gia của vũ đạo mà chỉ thấy nổi rõ vai trò của âm nhạc. Có lẽ điều đó xuất phát từ việc nghệ thuật múa của người Tày không phát triển lắm so với một số dân tộc khác. Vũ đạo chỉ tham gia vào diễn xướng dân ca nghi lễ chứ không xuất hiện trong diễn xướng DCTTSH Tày.

\section{Nguyên nhân sự khác biệt trong diễn xướng hát đối đáp DCTTSH của hai dân tộc Tày, Thái}

Các đặc điểm diễn xướng hát đối đáp DCTTSH của hai dân tộc Tày, Thái đều ẩn chứa những nội hàm văn hóa sâu xa. Trong đó, nguyên nhân chủ yếu tạo nên sự khác biệt được quy định bởi quá trình giao lưu, tiếp biến văn hóa của từng dân tộc trong lịch sử. Quá trình ấy diễn ra trên ba hướng cơ bản, với đối tượng giao lưu chính là văn hóa Kinh và văn hóa Hán.

Hướng thứ nhất là sự tiếp biến về văn hóa trong quá trình hình thành và phát triển dân tộc. Từ nguồn gốc dân tộc, có thể thấy người Tày và người Thái đều thuộc khối siêu tộc Bách Việt ở miền nam Trung Quốc thời cổ đại. Dưới thời Tần Hán, các nhóm Việt đều chịu sự thống trị của vương triều trung nguyên, trừ Điền Việt tức bộ phận tổ thành người Thái đen thiên di vào Tây Bắc Việt Nam sau này. Như thế, xét từ lịch sử dân tộc, có thể thấy rằng người Thái không chịu ảnh hưởng của văn hóa Hán, trong khi người Tày có chịu ảnh hưởng. Tiếp đó, quá trình thiên di của người Tày vào Việt Nam không mang tính chất ồ ạt, địa bàn phân cư cũng ổn định hơn người Thái, tạo điều kiện cho việc bảo lưu những giá trị văn hóa tiếp thu của người Hán. Bên cạnh đó, diện mạo dân tộc Tày ở Đông Bắc như ngày nay có sự kết hợp của bộ phận Tày gốc Kinh, Tày gốc Nùng và nhóm những người đồng tộc đến từ Trung Quốc. Sự hỗn hợp về mặt nhân chủng như trên là cơ sở thuận lợi cho sự giao lưu với văn hóa Kinh thông qua bộ phận người Tày gốc Kinh, giao lưu với văn hóa Hán thông qua bộ phận người Tày gốc Nùng và nhóm những người đồng tộc ở bên kia biên giới.

Hướng thứ hai là quá trình giao lưu giữa dân tộc chủ thể, chiếm đa số với dân tộc thiểu số. Trong suốt thời kì phong kiến độc lập, để củng cố quốc gia, các vương triều phong kiến ở đồng bằng vẫn luôn muốn vươn tầm ảnh hưởng lên vùng cư trú của các dân tộc thiểu số, song các nhà cầm quyền chỉ có thể làm được điều đó với xứ Tày chứ không làm được triệt để với xứ Thái.

Hướng thứ ba là quá trình giao lưu tự nhiên giữa các dân tộc chung sống trên một phạm vi địa lí với kết quả là sự hòa hợp về văn hóa. Theo đó, người Tày có sự gần gũi về văn hóa với người Kinh, Hán, Nùng..., văn hóa Thái lại có sự gặp gỡ với văn hóa của các tộc Môn Khơ Me.

Kết quả của cả ba hướng này là sự ảnh hưởng sâu đậm của văn hóa Kinh, Hán lên văn hóa Tày và sự độc lập tương đối của văn hóa Thái so với văn hóa Kinh, Hán. Trong diễn xướng hát đối đáp DCTTSH Tày, dấu vết của sự ảnh hưởng nằm ở tính ổn định và tổ chức cao bởi sự phổ biến của sự diễn xướng có lề lối với quy định rõ ràng về không gian, thời gian, mục đích của diễn xướng, diễn xướng theo sách và có thầy dẫn. Trong khi đó, văn hóa Thái ít có sự giao lưu với văn hóa Kinh nên về cơ bản văn hóa Thái là nền văn hóa nội sinh. Điều đó thể hiện trong diễn xướng hát đối đáp DCTTSH là sự diễn xướng mang tính tự do và sinh động: tự do về không gian, thời gian tổ chức, phổ biến cả hai dạng thức tổ chức là nguyên sơ và có thể thức; sinh động bởi có sự tham gia của vũ đạo.

\section{Kết luận}

Là những sinh hoạt văn hóa dân gian đóng vai trò to lớn trong việc cố kết cộng đồng, diễn xướng hát đối đáp DCTTSH của người Tày và người Thái có những khác biệt nhất định, thể hiện ở tính tổ chức của diễn xướng, không gian, thời gian, dạng diễn xướng theo sách và sự tham gia của vũ đạo vào diễn xướng. Từ sự khác nhau đó, có thể thấy diễn xướng của người Thái nổi bật ở sự tự do, phóng khoáng và sinh động, diễn xướng của người Tày nổi bật ở sự ổn định, có lề lối.

Từ việc so sánh, làm rõ những điểm riêng biệt giữa diễn xướng hát đối đáp DCTTSH của người Tày và người Thái, chỉ ra các lớp văn hóa được ẩn chứa trong đó, chúng tôi hướng tới việc chỉ ra cái đặc thù trong văn hóa của mỗi dân tộc. Những đặc điểm khác biệt thể hiện bản sắc văn hóa dân tộc, góp phần cung cấp thêm một cứ liệu để hai dân tộc tự khẳng định mình, chứng minh cho sự khác biệt và chia tách của hai dân tộc vốn cùng chung ngữ hệ và có nhiều đặc điểm gần gũi về địa văn hóa, sử văn hóa.

\section{TÀI LIỆU THAM KHẢO}

1. Hoàng Triều Ân, Hoàng Quyết (sưu tầm và biên soạn), Thành ngũ - Tục ngũ - Ca dao dân tộc Tày, Nxb Văn hóa Thông tin, Hà Nội, 2014. 
2. Nguyễn Văn Hòa (sưu tầm, biên dịch), Truyện cổ và dân ca Thái vùng Tây Bắc Việt Nam, Nxb Văn hóa dân tộc, Hà Nội, 2001.

3. Vi Hồng, Sli lươn dân ca trũ tình Tày Nùng, $\mathrm{Nxb}$ Văn hóa, Hà Nội, 1979.

4. Nguyễn Xuân Kính, Con người, môi trường và văn hóa, Nxb Khoa học Xã hội, Hà Nội, 2013.

5. Hoàng Ngọc La (chủ biên), Văn hóa dân gian Tày, Sở Văn hóa thông tin Thái Nguyên xuất bản, 2002.

6. Hoàng Văn Páo (chủ biên), Luợn Tày: Lươn Tày Lạng Sơn, luợn slương, Nxb Văn hóa dân tộc, Hà Nội, 2012.
7. Dương Đình Minh Sơn, Ngôn ngũ với việc hình thành âm điệu đặc trung trong dân ca Thái Tây Bắc Việt Nam, Nxb Âm nhạc, Hà Nội, 2001.

8. Kiều Trung Sơn, "Nhìn lại khái niệm diễn xướng", Tạp chí Văn hóa dân gian, số 5/2012, tr.3-12.

9. Viện Nghiên cứu Văn hóa, Tổng tập văn học dân gian các dân tộc thiểu số Việt Nam, tập 23 - Nhận định và tra cúu, Nxb Khoa học Xã hội, Hà Nội. 2010.

10. La Công Ý, Đến với người Tày và văn hóa Tày, Nxb Khoa học Xã hội, Hà Nội, 2010.

\section{Difference in the choral performaces of Tay and Thai daily lyric folk}

\section{Ha Xuan Huong}

\section{Article info}

\section{Recieved:}

02/5/2019

Accepted:

$10 / 6 / 2019$

Keywords:

Difference; the choral performances; daily lyric folk; the Tay; the Thai.

\begin{abstract}
As ethnic groups of cultural subjects in the Northeast and Northwest, the Tay and Thai people have a very special cultural life, including the choral performaces of daily lyric folk. By comparison, we see the choral performaces of Tay and Thai daily lyric folk activities with differences in organization, space, time, form of performance according to books, participation of choreographers. From there, it can be seen that the choral performaces of Tay daily lyric folk stood out in the organization and stability; the choral performaces of Thai daily lyric folk stand out in freedom and vividness. Differences are the basis for awareness of the cultural identity of the Tay and Thai peoples.
\end{abstract}

